\title{
ENTREVISTA COM O DRAMATURGO PORTUGUES ARMANDO NASCIMENTO ROSA
}

http://dx.doi.org/10.11606/issn.2175-3180.v13i24p143-155*

Por Rosana Baú Rabello

Armando Nascimento Rosa é uma das mais novas vozes do teatro português. Dentre as suas peças encenadas e/ou publicadas, contam-se títulos como: Antígona gelada (2008); Cabaré de Ofélia (2007); O eunuco de Inês de Castro (2006); Maria de Magdala (2005); O túnel dos ratos (2004); Um Édipo (2003); Audição - com Daisy ao vivo no Odre Marítimo (2002); e Espera Apócrifa (2000). Várias de suas peças foram traduzidas e publicadas em inglês e castelhano e tiveram encenação e/ou leituras dramáticas realizadas em Madrid, Londres, Nova Iorque, Zurique e Brasil.

O processo criativo do teatro do autor trabalha com aspectos ligados à tradição do teatro ocidental, de maneira a revisitar modos e temas importantes para o teatro, a literatura, a psicanálise, a mitocrítica. Rosa é um autor bastante novo, nascido em 1966, já próximo daquilo que seria o final da ditadura salazarista. Apesar de tão jovem, é um autor muito profícuo, com diversas peças publicadas e dois livros de ensaio: $\mathrm{O}$ seu projeto de mestrado sobre o teatro beckettiano (Falar no deserto, 2000) e o seu projeto de doutorado (As Máscaras Nigromantes: uma leitura do teatro escrito de António Patrício, 2003).

\footnotetext{
* Publicada originalmente na revista Desassossego, v. 3, n. 6, dez/2011: https://www.revistas.usp.br/desassossego/issue/view/2851

DOI original: http://dx.doi.org/10.11606/issn.2175-3180.v3i6p135-146

I Universidade de São Paulo, São Paulo, Brasil.
} 
Além de um intenso processo colaborativo com o Cendrev (Centro Dramático de Évora), um importante grupo de criação e difusão de espetáculos, com mais de trinta anos de história, Rosa é professor adjunto da Escola Superior de Teatro e Cinema no Instituto Politécnico de Lisboa.

Seu trabalho é bastante interessante, pois nos faz refletir sobre uma parte considerável do pensamento e da criação artística nesta virada de século. Independente do nome dado às produções mais recentes (pósmoderno, contemporâneo), fato é que muitas das obras contemporâneas têm empenhado esforço na autoreflexividade e autocrítica. $\mathrm{O}$ teatro de Rosa lida com isso por meio de recursos comuns: a intertextualidade, a paródia, a metadiscursividade. Ele reflete por meio desses recursos sobre suas referências e sobre aquilo que é tomado como paradigma na construção da história, dos mitos, olhando de perspectivas diversas para os discursos constituídos, ressignificando-os.

Seja no contexto da história, da literatura ou das narrativas míticas, de modo geral, o autor propõe revisar histórias aparentemente muito conhecidas, as quais, muitas vezes, se cristalizaram no imaginário ocidental, mas que não deixam de ser passíveis de uma nova visada.

Fazendo uma compilação e mistura de várias versões da História, dos mitos e das narrativas que se tornaram paradigmáticas, o autor orquestra alguns motivos importantes na formação do imaginário ocidental.

Édipo, por exemplo, é a personagem que se cristalizou como aquele desgraçado rei tebano que, na versão mais conhecido do seu mito, assassinou o pai e casou com a própria mãe. O enredo pode até ser comum em várias das materializações artísticas que se fazem desse mito, mas, como é possível levantar em diferentes peças, filmes e pinturas que o retratam, cada uma das releituras vai apresentar um recorte diferente para essa mesma história.

Entendendo isso, em sua releitura de Édipo, por exemplo, Rosa vai discutir esse desejo de sufocar as gerações futuras, com medo de que essas assumam poder e importância que obliterem a imagem do "pai" (seja do pai história, instituições, imagens sedimentadas, pai texto). O próprio autor vai defender a ideia de que, na cena do teatro português contemporâneo muitas vezes a geração sênior tenta abafar e solapar as inovações e a voz das novas gerações. 
De qualquer forma, Rosa procura não ocultar essas vozes que construíram o passado ou as suas versões. Ele dialoga com elas por meio da paródia, que cria um distanciamento crítico entre o texto referência e a paródia criada.

Nessa compilação e mistura das várias versões da história, o autor também vai dar voz àquelas personagens marginalizadas, ocultadas pelo discurso dominante, o que vai ajudar a criar essa visão crítica, distanciada, própria da paródia como a entende Linda Hutcheon, ou seja, como repetição com distância crítica (1989).

Em sua última visita ao Brasil, com o intuito de participar de um Seminário Internacional, o autor ofereceu gentilmente a entrevista que segue:

ROSANA BAÚ RABELLO: Armando, você faz essa distinção entre escrever teatro e escrever para teatro. Gostaria que você falasse um pouco a respeito.

ARMANDO NASCIMENTO ROSA: Eu digo isso e tenho essa conviçcão, porque penso que há uma especificidade da escrita para a cena que nos autoriza, ao contrário de muitos autores, a falar de teatro escrito. Aliás, eu uso desse conceito na leitura que faço do António Patrício. Quando falo de teatro escrito é porque há realmente uma especificidade do texto que é escrito para a cena que nos autoriza a dizer isso. É evidente que não estamos a falar de teatro que seja representado. Uma coisa é a performatividade desse texto em cena, outra coisa é a sua qualidade cênica que nos permite dizer que é um texto escrito para a cena. Daí eu usar esse jogo de palavras. Porque aquilo que eu persigo é a escrita de texto que tenham sua eficácia cênica no momento próprio que os abordamos na leitura. Porque outra coisa é dizer que encontramos textos que tem uma pertinência cênica. Por exemplo, há contos de Marguerite Yourcenar que tenham sido encenados vezes sem conta, porque são textos que tem qualidades cênicas, qualidades dramáticas. Mas ela os escreveu como contos. Eu não diria que era um teatro escrito, mas colhemos o teatro implícito neles. Não é meu caso, eu escrevo deliberadamente para a cena. Então digo que escrevo teatro.

RBR: Você também fala sobre a construção dos textos, que passa por uma pesquisa e por um processo criativo. Gostaria que você contasse sobre 
como você encontra esse equilíbrio entre a pesquisa e as liberdades tomadas, por exemplo, em Um Édipo, mitodrama fantasmático em um acto (2003), quanto reinventa a cena do parricídio, com a presença de Crisipo como fantasma encarnado.

ANR: Vou tomar como exemplo o caso que tu enuncias do Édipo. Talvez seja um exemplo dessas liberdades e ao mesmo tempo do que eu faço com os materiais com que me confronto. Eu gosto de me documentar na medida do possível. Quando estou a trabalhar um tema, personagem, enredo que já foi trabalhado vezes sem conta no passado e sobre o qual há muita bibliografia, do ponto de vista da criação dramatúrgica, ou do ponto de vista do ensaio crítico acerca, procuro me documentar. Às vezes até é muito engraçado porque as informações vêm me parar às mãos no momento em que estou a trabalhá-las. Às vezes não preciso muito procurar. Com minha peça A última lição de Hipátia (2004) eu tenho histórias absolutamente fabulosas de eu estar em sebos e vir me parar as mãos uma tradução de um Paladas de Alexandria, que era amigo de Hipátia, e encontro num sebo uma tradução feita aqui no Brasil dos epigramas de Paladas de Alexandria, um deles dedicado à Hipátia. Eu jamais sabia que havia um indivíduo chamado Paladas e que era amigo de Hipátia.

No caso do parricídio, do Édipo, eu tinha ali duas referências, de uma versão mais corrente do mito, a que aparece na versão do Édipo de Sófocles, que é precisamente a questão do encontro de Édipo e aquele desconhecido que ele não faz a mínima idéia que é seu pai biológico. E há, por outro lado, uma situação que eu chamo de a versão "queer", relacionada com o Crisipo. Porque há duas versões. Uma que diz que Laio teria raptado Crisipo e assediado sexualmente e na qual Crisipo se suicida. Mas há outra versão, muito mais escabrosa, em que ele não se suicidou coisa nenhuma. Ele sobreviveu feliz da vida, e mais, há um momento em que Édipo cruza com Laio e disputa aquele jovem, os dois disputam Crisipo. Pensei: vou me utilizar da versão mais dominante e também aquela que melhor me serviria dramaticamente em relação à morte de Crisipo, para a questão da maldição, (porque essa versão alternativa deixa a maldição sem efeito). E o que fiz foi utilizar elementos das duas sem ser fiel a nenhuma delas. Na peça, eles encontram-se em uma encruzilhada, não se conhecem, não sabem quem são, mas Laio está acompanhado do jovem Crisipo, mas não é Crisipo vivo, é o fantasma de Crisipo, que por 
uma razão, que os deuses desejaram, torna-se visível aos olhos de Édipo. Torna-se visível não só aos olhos de Laio como também aos olhos de Édipo e, por isso, Édipo mata o pai numa manifestação da homofobia, por estarem aqueles dois enrolados no meio da via. Há um elemento do tal drama satírico que a peça tem, mas ao mesmo tempo a criação de sentidos novos, porque faz de Édipo um agente dessa violência homofóbica. Quando isso me surgiu, pensei que havia ali uma via interessante de explorar a situação, introduzindo um elemento mais perturbador ainda. Portanto, regra geral do que eu dizia é que eu gosto de me documentar para me sentir com segurança para inventar. E, depois, sendo assim, me sinto com muito mais liberdade. Posso dizer, eu inventei assim, porque fui por esse caminho. E depois, é claro, há um certo momento em que não sei dizer de onde aquilo surge, mas funciona assim. E, é claro, o António Patrício dizia isso, que não éramos nós que escolhíamos os temas, os temas é que nos escolhiam.

É evidente que há sempre uma espécie de mapa consciente que se possa associar a cada uma dessas peças, mas depois há outras matérias que já transcendem relativamente à possibilidade de escrever detalhadamente porque elas vêm a ser assim deste modo. Às vezes há também cumplicidades. Eu posso dizer que Um Édipo, eu não teria escrito como foi se não houvesse aquela conversa que tive com Miguel Loureiro, o jovem encenador que pela primeira levou-a a cena, e eu ter percebido que ele estava muito motivado por este tema. Por outro lado, embora eu já tivesse tido vontade de escrever essa peça, eu sabia: quem é que em Portugal vai encenar uma peça destas? Que traz esta situação incomoda sobre Édipo? Ou seja, não é simples, não é por acaso que foi um encenador da geração dos 30 anos e não um diretor mais velho. Isso falando do panorama do teatro em Portugal, em outra latitude poderia ser de outro modo.

Assim como minha outra peça, Audição com Daisy ao vivo no Odre Marítimo (2002). Eugênia Vasques me dizia que ninguém da geração "sênior" encenaria essa peça. Eles têm um pudor específico em de repente colocar um ator que faz uma personagem como essa da Daisy (uma drag queen) e que nos baralha, e que não é propriamente um baralhar, é explicitar o próprio universo pessoano da máscara. Mas ao mesmo tempo é interessante esses testes, como a questão do silêncio da imprensa em relação à Maria de Magdala (2005). Em relação a isto, eu penso que está peça funciona como uma pedrada no charco, porque leva à cena matérias que 
normalmente as pessoas não estão à espera de ver, matérias de natureza religiosa, cristianismo primitivo, mulheres na igreja, e isso tudo no teatro. E depois, o fato de ficarem um bocado confusos, e pensarem: e agora, onde encaixamos esta peça, como a classificamos? Eu sinto isso com minha dramaturgia: onde nós encaixamos a dramaturgia de Nascimento Rosa? Porque isso não é facilmente catalogável. Mas isso também me diverte, dáme uma grande motivação, porque no fundo nós estamos aí para descobrir e não para engavetar, nem para etiquetar.

RBR: Você trabalha sempre com temas digamos ocultados, recalcados pela história e pelos paradigmas. Nesse sentido, você vê seu teatro como um teatro político?

ANR: Eu diria que há sempre essa situação. Eu penso que meu teatro tem essa natureza múltipla. Assim como nessas minhas especulações em que eu falo do teatro Dramático, Arquetípico, Cenoplástico, Crítico e depois Gnóstico que reúne isso tudo.

Eu creio que há elementos que me motivam e que tem a ver com essa destinação para a polis, no seu sentido mais lato. E aí eu diria que há uma dimensão política no meu teatro, sem dúvida. Porque ao trazer o mito de Inês de Castro em O Eunuco de Castro (2005), que é uma espécie de mito paradigmático da identidade portuguesa, e dar-lhe um tratamento novo: isto é um gesto político. Assim como em Antígona Gelada (2008). Antígona é uma fábula política, passada numa sociedade inventada, mas de repente nós encontramos vias de comunicação e identificação com a nossa, ainda que nessa transfiguração e nessa efabulação de ficção científica. Eu não rejeito essa caracterização. O que direi é que aquilo que faço não se esgota numa espécie de militância ao modo que se entenderia nos anos 1940, quando falávamos relativamente ao teatro de Brecht, ou anteriormente ainda em relação ao Piscator. Porque também os contextos sócio-políticos são inteiramente outros. Talvez haja hoje, como muitas vezes eu brinco, uma espécie de "psicopolítica", como por exemplo, é o caso da última fase do Augusto Boal e sua aproximação do teatro do oprimido às psicoterapias. Porque ele percebe que o oprimido está na psique. Eu encontro muitas afinidades com essa reflexão e esse caminho dele também é uma indicação relativamente àquilo que são os percursos, aquilo que de repente surpreende como caminho possível, ou algo familiar, o impacto 
das coisas que vou fazendo. Porque é sempre essa situação: o teatro não tem hoje a centralidade, do ponto de vista cultural, que já teve no passado, mas continua a ter a sua pertinência e há um lugar insubstituível, neste sentido. Há coisas que acontecem no teatro que não acontecem em lugar nenhum mais. Não tenho preconceitos em falar da política porque o teatro na sua origem era da e para a polis e conforme as modalidades mais complexas e mais pós-modernas que temos hoje da vivência do político, o certo é que continuamos a ter um espaço público e o teatro é uma arte pública por excelência. E nesse sentido eu reivindico essa qualidade do político para o teatro.

RBR: A professora e crítica do teatro português Eugênia Vasques faz um comentário muito construtivo a respeito de seu teatro e fala de uma identidade poética encontrada no conjunto de sua obra. Gostaria que você comentasse um pouco sobre a multiplicidade de seu trabalho, com temas e modos de construção teatral muito diversos, ao mesmo tempo em que você constrói essa identidade reconhecida por Eugênia Vasques.

ANR: Eu identifico linhas condutoras que tem a ver com essa identidade de que falas e que Eugênia Vasques encontrou. O que penso também que cada uma dessas aventuras, dessas experiências está muito relacionada com aquilo sobre o que eu me interrogo. Pegando do ponto de vista dessa abordagem, como traduzi-la do ponto de vista dramático? E eu penso que cada uma de minhas peças vai encontrando as suas linhas de solução. E essas linhas de solução por vezes podem divergir bastante. Se compararmos Um Édipo com Antígona Gelada, são modos de abordar completamente diferentes, a partir de materiais que são muito próximos. É evidente que ao lê-los sentimos afinidades. Há modos de ver, embora em termos de forma dramática eles se distanciem. Eu penso que existe essa multiplicidade no modo como essas experiências se desenvolvem, ainda que existam "núcleos duros" que permanecem comuns e que estão presentes na Antígona Gelada, no Túnel dos Ratos ou no Lianor no País sem Pilhas. Eu penso que Eugênia tem uma intuição profunda em relação a isso porque ela começou a ler minhas peças muito cedo, ainda num momento em que meu teatro não era nem sequer representado. E ela, quando foi o lançamento em livro da Lianor no país sem pilhas, disse-me algo muito engraçado, disse: Armando escreveu na Lianor uma síntese do teatro que 
escreveu até agora. Ou seja, compor uma fábula infanto-juvenil com linhas do que ele tinha já desde a primeira peça. Isso se deve ao fato de ela ser uma leitora muito atenta, por isso, identifica esses nexos.

Agora, é evidente que essa linha encontra situações diversas, e ela própria diz que gosta mais de Um Édipo do que de outras peças. É evidente que depois os leitores reagem. A Hipátia é, por exemplo, uma peça interessante que tem experiência apenas como leitura. Como é uma peça muito diversa, há pessoas que ficam fascinadas e querem ver na cena, mas há outros que se sentem incomodados com ela, incomodados no sentido de achar que há uma dimensão de violência que se torna um bocado irrespirável. E reconheço que há uma dimensão de crueldade que ali está, mas a história tem realmente ingredientes de grande crueldade. Estamos a falar de alguém que foi barbaramente assassinada. Nesse sentido não posso dizer que haja uma espécie de uniformidade em relação a esse processo de recepção.

E desse ponto de vista da multiplicidade e da identidade é uma dialética que está aí. Mas de qualquer forma afirmo que cada peça vai, dentro de seu núcleo temático, em busca da forma em que se manifesta.

Por exemplo, em Visita na Prisão (2009), eu tento mimetizar de uma forma muito livre uma espécie de texto que não é um texto contemporâneo, mas estou consciente que não é nenhuma arqueologia do dizer português. Há pinceladas de uma época, mas essas pinceladas de época estão em um texto que pretende estabelecer uma comunicação com os dias de hoje. Por isso, cada obra vai me ditando sua forma. Eu, no início, costumava dizer que escrevia para o teatro peças que eu gostaria de ver encenadas.

RBR: O metateatro, por exemplo, é um recurso bastante recorrente em suas peças e pode denotar algo sobre essa identidade poética e dramática de sua obra. Fale um pouco a respeito desse recurso.

ANR: Costumo dizer que há elementos que entraram na gramática do teatral e que vêm fazer parte da nossa familiaridade. Eu já não digo mais aqui está o Brecht, ali está o Artaud, ali está o Pirandello. Aquilo já está integrado, já está na epiderme.

Como eu tenho realmente essa paixão pelo teatral, tanto me empolga uma boa peça do Pirandello, como Tchecov, como de Shakespeare, de Beckett. Mas não á a toa que digo esses nomes. Pois são 
aqueles que constituíram novos acréscimos, novas visões, novas formas de fazer teatro, e de escrever, e por isso, eu penso que de fato essa herança viva fala em nós. Isso depois se projeta nessa situação do teatro que reflete ironicamente sobre si mesmo. Eu penso que aquilo que há de metateatro no meu teatro tem sempre a ver com isso. Um pouco como Humberto Eco quando explica a diferença entre o moderno e o pós-moderno, da questão de haver essa consciência acrescida de... Sem querer dizer agora que isso é tudo pós-moderno. Mas essa situação de que temos consciência desse legado e esse legado trabalha em nós, mas sem o preconceito de que agora isso é uma coisa que já faz parte de algo conhecido, então eu quero evitar isso. Eu penso que o teatro deve sempre jogar com o que é seu, com o que ele já se apropriou. Não digo que estarei a criar, a inventar formas novas. Se elas surgirem tanto melhor, não é? Se as pessoas reconhecerem como qualquer coisa de inovação, tanto melhor. Mas eu creio que cada uma das obras tem tido essa procura. E esses "metateatros" têm manifestado formas diferentes em cada uma dessas peças. Agora é evidente, para meu gosto, na reflexão sobre o teatro, acho que o metadiscurso é inerente ao próprio texto, porque o texto escrito está a olhar ironicamente sobre si mesmo e daí eu gostar muito desse jogo que o teatro faz consigo mesmo, divertir-me com isso. E não é só uma questão de diversão, é porque isso produz sentidos que vão a diversos quadrantes. Isso é também algo que dinamiza o meu processo de criação. É quase como se dissesse: e agora, como jogar com a perda da inocência?

Na Visita na Prisão, ou O Último Sermão de Padre António Vieira (2009), os espectadores são levados a pensar se era possível que uma mulher, no século XVIII, se comportasse como a Madre Paula retratada na peça, se diria aquelas coisas. Isso é interessante, de repente o espectador fica incomodado. Gosto disso, porque o teatro não é arqueologia. Mas agradame o processo do próprio teatro ser, a própria escrita dramática ser ela própria um veículo de reflexão sobre si própria, um metadiscurso, sem uma situação de um hermetismo, de um círculo fechado. Isso também não me interessa. Gosto que seja realmente essa leitura aberta, que permite um processo de ironização, de paródia.

Paródia é uma palavra muito elucidativa a este respeito porque é ode ao lado, a ode que se escreve ao lado, ou seja, ela tem um modelo anterior sobre o qual ela trabalha. E isso me interessa, porque todos esses meus experimentos podem ser vistos como experimentos paródicos, por 
mais matéria trágica que lá exista. Mas, não será isso também o teatro? A mimese teatral não é por sua natureza paródica? É sempre uma ode ao lado daquilo que é o nosso olhar sobre o real, e a nossa recriação dele enquanto mimese, enquanto representação. Se calhar é isso a própria matéria prima do teatro. E não estou fazendo mais do que retratar isso e dizer é isto, o teatro é isto.

RBR: A paródia, tal como a entende Linda Hutcheon, não é apenas um processo cômico. A "tragédia", em um sentido moderno, também poderia estar caracterizada como uma leitura paródica, uma recriação com distanciamento crítico e irônico. Você acredita que isto está presente em seu trabalho?

ANR: A Antígona Gelada (2008), independentemente de elementos estritamente cômicos que ela possa ter pontuais, eu penso que pode entrar em diálogo com essa situação que você está a dizer. De fato, há matriz trágica nesta história que é terrível. O que eu faço a esta minha personagem! Pobre da Antígona! Há ali uma dimensão trágica.

Chega um ponto em que ela (Antígona) não tem saída, dentro do retrato humano que eu faço dela. Mas não deixa de ter a paródia, porque é uma "ode ao lado", é a Tebas 9. Aliás, aquela fala do Creonte que diz: "já houve muitas Antígonas, muitos Creontes antes de nós...". Então o texto, a partir da fala dessa personagem, torna-se eminentemente consciente e afirmativo disso. Mas, a despeito disso, em vez de a história se desconstruir, ainda abre para outro horizonte, porque, de repente, saímos dali, e aí o incômodo do espectador, essa situação de tirar um tapete previsível para se abrir um rasgão.

Eu penso que faz sentido e creio que naquilo que me é dado ver, as leituras, as teorizações em torno do paródico certamente encontrarão muita ressonância em relação aquilo que escrevo. Porque isso são realmente odes ao lado.

RBR: Você tem esse trabalho múltiplo e, apesar disso, tem também uma identidade bem marcada. Tem essa questão dual no seu trabalho. Você é autor que participa da concepção cênica de suas peças e, ao mesmo tempo, como teórico, como pensador do seu próprio trabalho, você recorre a algumas categorizações como mitodrama paródico, drama satírico, 
mitodrama fantasmático, fabula gnóstica. Eu gostaria que você falasse um pouco sobre o porquê dessas escolhas de categorização?

ANR: Cada categorização emerge do universo, do tom, do imaginário de cada uma das peças. Eu reconheço que há algumas que partilham mais afinidades do que outras. Não é por acaso que, por exemplo, eu chamo $U m$ Édipo de "mitodrama fantasmático em um acto" e ao Nória e Prometeu, "um mitodrama paródico em sete cenas". Há elementos de afinidade da matéria prima com que trabalham as duas peças, mas o modo como trabalho é diferente. $\mathrm{O}$ fantasmático ali me surgiu da insistência daquele confronto entre os que estão vivos e os que estão mortos e esse diálogo que é mantido (e que, se calhar, se podia nomear de "fantasmáticos" muitos outros textos). O haver essas designações, às vezes são espécies de pistas. Não sei se são apenas para os destinatários como para mim próprio. Mas o meu objetivo é de que em vez de dar trabalho para os leitores/espectadores, eu possa dotá-los de algum instrumento de leitura. Esse é um objetivo. Não é para complicar, mas para simplificar compreendendo.

Por exemplo, Maria de Magdala, fábula gnóstica (2005). Porque eu senti a necessidade de fazer isso? Porque eu quis sublinhar que aquilo é uma fábula e a fábula remete logo para a questão imaginária, inventada. Então, para deixar a coisa inequívoca, isto é uma fábula e gnóstica, porque há muitos elementos do imaginário que fiam-se à filosofia gnóstica, que "enformam" aquela fábula. Portanto, lidando com o cristianismo primitivo, que era gnóstico. Por isso, ao dizer aquilo, dou uma pista ao leitor/espectador de que aquilo é uma fábula gnóstica.

Em relação ao Túnel dos Ratos (2004), a edição portuguesa ainda não tem isso, mas na edição inglesa houve a necessidade de colocar "dark comedie". Se calhar, faz sentido em relação à edição portuguesa, uma vez que ela volte a ser editada, colocar "comédia sombria". Esta peça é isso. Essa tradução foi sugerida por um amigo, leitor e tradutor (dark comedy para comédias sombrias). Ele me despertou para essa designação. Eu devo a ele a patente de comédia sombria usando-a hoje aqui e quando a colocar relativamente ao Túnel dos Ratos.

Em A Visita na Prisão, há a designação fiç̧ão histórico-cênica. Aqui a mesma coisa. Olha-se aqui o último sermão de António Vieira: é fição. "Histórico-cênica" porque jogo com o histórico e jogo com a cena. Como disse a pouco, tento ser súdito das duas dimensões, ou das três, da ficção, 
da história e da cena. Por exemplo, em relação à linguagem, eu tenho intenção de estar a fazer jus a essa destinação cênica. Por isso, aquilo que posso dizer é que a categorização diz respeito sempre a uma espécie de identidade de cada uma das obras. Ainda que possa haver obras que tem afinidades, o que leva a que algumas categorizações transitem.

No posfácio à Audição com Daisy ao vivo no Odre Marítimo coloquei um título que soa algo pomposo: "sonata cênica e xamânica". Teço então umas conjecturas em relação ao xamanismo e sobre a própria transição entre o sexo do xamã ou da xamã atestado pela literatura antropológica e que ali me servia muito bem com Daisy, por ser ela uma figura, uma xamã do music hall. Às vezes essas coisas criam sinergias de sentido. É por aí que eu vejo essas possíveis categorizações.

Eu penso que o fato também de gostar muito de fazer o trabalho hermenêutico, de decifração, acaba por contagiar as minhas obras também com matéria para isso. Mas não tenho a realidade de dizer aquelas coisas que o Joyce e o Beckett diziam de dar trabalho aos acadêmicos. Agora, se vocês (estudiosos) se sentem motivados para trabalhar com isso, tanto melhor, vão em frente.

\section{REFERENCIA}

HUTCHEON. L. Uma Teoria da Paródia. Lisboa: Edições 70, 1989.

\section{REFERENCIAS DE ALGUNS TRABALHOS PUBLICADOS PELO AUTOR}

ROSA, Armando Nascimento. Antígona Gelada. Prefácio de Maria do Céu Fialho. Coimbra: Fluir Perene /Centro de Estudos Clássicos e Humanísticos da Universidade de Coimbra, 2008.

ROSA, Armando Nascimento. As máscaras nigromantes. Uma leitura do teatro escrito de António Patrício. Lisboa: Assírio \& Alvim, 2003.

ROSA, Armando Nascimento. Audição - Com Daisy ao vivo no Odre Marítimo. Évora: Casa do Sul, 2002.

ROSA, Armando Nascimento. A última lição de Hipátia seguido de O túnel dos ratos. Porto: Campo das Letras, 2004.

ROSA, Armando Nascimento. Lianor no país sem pilhas. Uma peça teatral infanto-juvenil. Porto: Campo das Letras, 2001. 
ROSA, Armando Nascimento. Maria de Magdala. Fábula gnóstica. Lisboa: Parceria A. M. Pereira, 2005.

ROSA, Armando Nascimento. Não és Beckett, não és nada. Uma paródia beckettiana. Lisboa: Apenas Livros, 2009.

ROSA, Armando Nascimento. Nória e Prometeu. Palavras do Fogo. Mitodrama paródico em sete cenas. Lisboa: edição online de 2004, disponível em http://www.triplov.org/teatro/armando_nascimento_rosa/noria_e_prome teu/index.htm

ROSA, Armando Nascimento. O Eunuco de Inês de Castro. Teatro no país dos mortos. Prefácio de Patrícia da Silva Cardoso. Évora: Casa do Sul, 2006.

ROSA, Armando Nascimento. Um Édipo - O drama ocultado. Mitodrama fantasmático em um acto. Évora: Casa do Sul, 2003.

ROSA, Armando Nascimento. Visita na prisão ou O último sermão de António Vieira. Ficção histórico-cénica. Lisboa: Assírio \& Alvim, 2009.

\section{Licença: () (1) (\$)}

Concepção e realização da entrevista:

Rosana Baú Rabello

Doutora em Estudos Comparados de Literaturas de Língua Portuguesa pela Universidade de São Paulo. Mestra egressa do Programa de Pós-Graduação em Literatura Portuguesa da Universidade de São Paulo.

Contato: rosanabau@gmail.com 